\title{
Scientific Rationale for The Development of Low-Intensity Irrigation Systems in Azerbaijan
}

\author{
Qasım Ali oqlu Soltanzade \\ Azerbaijan University of Architecture and Buildings Doctorate \\ Volqa_5@mail.ru
}

\begin{abstract}
:
The results of the study revealed that the mismatch intensity rain rate of water absorption into the soil formation of a surface relief and soil erosion, uneven and shallow soaking imperfection open irrigation system at a superficial irrigation, the need for different irrigation methods in the growing and not growing periods, low coefficient land utilization, high cost of irrigation and other features are, to a certain extent in conflict with the requirements of watering cultivated with techniques for / of crops in an area at the deep groundwater.
\end{abstract}

Keywords: irrigation interval, irrigation, water capacity, groundwater, loam, a count unit, slope, soil fertility, and others.

\section{Introduction}

The increase in the production of agricultural crops is one of the priorities of agrarian production in Azerbaijan, both for meeting domestic needs and for exporting them. In solving this problem, a significant role belongs to the regions, the natural and climatic and economic and economic conditions of which are favorable for the successful development of irrigated agriculture.

And taking into account the long traditions and high level of professional training of agricultural specialists, the experience of the population and the transfer of this direction to the private sector, we can safely assert not only the development of mountain-irrigated agriculture in Azerbaijan in the coming years, but its revival based on the introduction of high-performance modern technologies Irrigation, as pulsed sprinkling, micro-irrigation, pulsed sprinkling of self-oscillating action, combined irrigation, impulse rain Self-oscillating action with automated control and a number of others.

Taking into account that the territory of Azerbaijan, which is the most favorable for cultivation of various types of crops by natural conditions, is located in zones of unstable and insufficient moisture, the intensification of fruit growing is possible only with the use of low-intensity irrigation systems. The necessity of using this kind of irrigation is also due to the increased demand of agricultural crops for moisture supply.

\section{Course of research and discussion of results:}

At the research facilities on the territory of the Republic, irrigation with micro-irrigation was carried out on medium and large slopes with a deep level of groundwater in the period 2005-2011.

At the same time, the cultivation of fruit trees with an irrigation device of the IDAD type and a micro-diver of various modifications was studied in the experimental site of the OEB of the Institute of Erosion and Irrigation of ANAS in the village of Malakh of the Shemakha district with an area of 4.82 hectares, in the period 2006-2010, in the Guba RWC in the Shahdag foothills on an area of 2.8 hectares, in the period 2004-2006, the work was also 
carried out in the Ganja district of the PAC in the village of Ganja, Bagmanly with an area of 4.45 hectares, in the period 2007-2011.

On irrigated light chestnut soils with a maximum moisture capacity of 3000-3100 m3 / ha and on deep-seated serozems Groundwater in the Alazansky valley of the Zakatala district in the period 2004-2006. 49 irrigations (500-650 m3 / ha) with an irrigation rate of $1890 \mathrm{m3} /$ ha were carried out. Only the upper layer of the soil (28$30 \mathrm{~cm}$ ) was moistened.

In the middle of July, the moisture content of the soil in the $30 \mathrm{~cm}$ layer decreased to $40 \%$ (from PPW), and in early September to 40-60\% (in the meter layer), which led to drying and a decrease in maize yield for silage and winter wheat. At the control plot (five irrigation on furrows with an irrigation rate of about $16,000 \mathrm{~m} 3 / \mathrm{ha}$ ), the humidity was $80-100 \%$ of PPV.

As a result of the research it was recommended to optimize the irrigation norm, the number of irrigation and the reduction of inter-irrigation periods; It was pointed out that it was expedient to use sprinkling with the use of the design developed by the author for the various modifications of microaraners tested at the experimental site, where watering along the furrows proved to be difficult, and in general impossible at all.

At the Institute of Erosion and Irrigation of ANAS with the participation of the author, experiments on irrigation with the IDAD apparatus and other modifications of the micro-irrigation irrigation technique of various types of agricultural crops on newly developed rainfed lands have been continued. On the example of the objects of research on which the experiments on the problems of the development of mountain-irrigated agriculture in the zones of Guba-Khachmas, Ganja-Gazakh, Garabagh, Upper Shirvan, Sheki-Zagatala and other regions of the republic were laid. It should be noted that in the zones of the experiment the soils are overlying, felling, loam (sierozem), and so on. Land with different soil characteristics, and in all these zones of the experiment the groundwater table is deep. With all this, it was planned to increase the density of plants and not to conduct inter-row treatments. From the experimental sites on the territory of the research objects, from which a "registration site" with more amicable shoots was isolated, divided into plots located at the site of the Shemakha OEB Institute of Erosion and Irrigation of ANAS in the village of Malham and Guba RAN in the foothills of Shahdag in the Guba area with a total area of 4, 82 hectares. (See Table 1).

Table 1

\begin{tabular}{|l|l|l|}
\hline Variants Width & Between rows, $\mathbf{m}$ & $\begin{array}{l}\text { Density of standing Plants, } \\
\text { thousand pieces / ha }\end{array}$ \\
\hline I & $4,5-5,0$ & 198 \\
II & $2,8-3,0$ & 280 \\
III & $2,2-2,5$ & 383 \\
\hline
\end{tabular}

During the vegetation period, 94 irrigation operations were carried out with an estimated irrigation rate of 4590 $\mathrm{m} 3$ / ha, which did not ensure normal soaking of the soil. 
The height of the fruit tree plants (about $5.0 \mathrm{~m}$ ) and the area along the humidification contour $(8-10 \mathrm{~m} 2)$, which was less than in furrow irrigation. The root system spread in the depth of the layer 2.0-2.5 $\mathrm{m}$, and with furrow irrigation in the depth of the layer more than $3.0 \mathrm{~m}$.

Moistening of such a small area was uneven, and yields in more moistened areas in apple orchards in the Guba region amounted to 210.9 centners per hectare and 189 centners per hectare at the Ganja RCAN, and on drained respectively 147.3 and 113.9 centner / ha.

The absence of cultivation of crops under the narrowed between rows led to a strong compaction of the soil and a decrease in water permeability, which increased the surface runoff during irrigation. The increase in the density of standing did not have a noticeable effect on the suppression of weeds. The development and growth of fruit (apple, pear, peach, persimmon, etc.) passed at a relative soil moisture of $20-40 \%$, soaking did not exceed $35 \mathrm{~cm}$. Originally in 2007-2008. In order to select the object of the study, we chose an experimental site in the OEB of the Erosion and Irrigation Institute of ANAS in the village of. Malham of the Shemakha district, on the OEP of the Guba RUCN in the Guba district. On the Shahdag foothills with a common

With an area of 2.8 hectares and on the EIA of Gyandja RUCN in the village. B / Bagmanli with an area of 4.45 hectares. It has been proven by the results of numerous experiments and researches, when choosing the right crop irrigation technology, it is imperative that we study the agro-soil, natural-economic, geographical relief of the territory and the degree of natural moisture and other characteristics based on the monitoring of multi-year data on the object of research, which we should study. specified in the example of the Shamakhi region, where it was decided to set up experiments in the period 2007-2009. for which it is shown in the table! water-physical and agro-chemical properties of the soil of the object of research, experiments that were carried out on the territory of the village Malham of the Shamakhi region. The results of our analysis showed that on the territory of the Shamakhi region widespread mainly degraded mountain brownish-brown soils are mainly widespread.

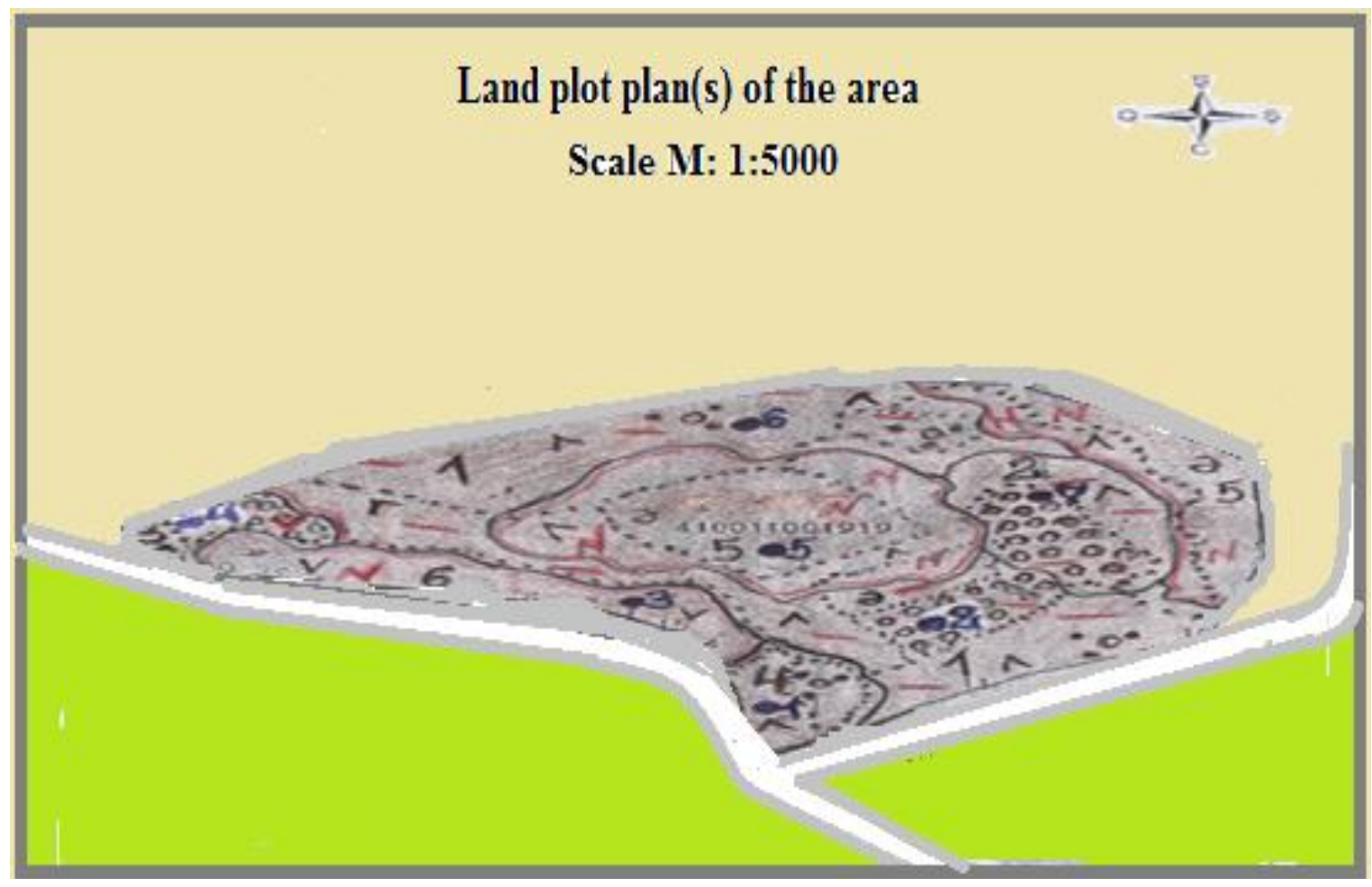

Fiq. 1 Land plot plan (s) of the areo the village Malham of the Shamakhi 
The climatic and climatic conditions of the Aral rocks are favorable for the cultivation of algae. Lacquer and highquality products are also available due to climate change and agricultural technology, taking into account the climatic conditions and biological characteristics of the plant. During their studies, they studied and studied the peculiarities of the local agrarian nature, the land plot, the armagic boy and the development of dynamics, macro-and microelement droppers applied using micro-irrigation technologies, drip irrigation, predominantly traditional irrigation dominant technology that allows the issuance of mineral fertilizers along with irrigation water for local nutrition of plants. As a result of the research, the most effective yields and indicators of $m$ acro and microclimate used in sewage treatment plants.

Macro and Macro elements together with irrigation water are provided as follows.

I. In the case of non-profit

1. Restless (without fertilizer)

2. N120P120K90-fnn

3.fund + B3Zn3

li. Do not drain

1. Restless (without fertilizer)

2. N120P120K90-fnn

3.fund + B3Zn3

III. Don't waste

1. Restless (without fertilizer)

2. N120P120K90-fnn

3.fund + B3Zn3

Each visitor has 3 dishes.

The soils of these massifs are medium-thick $(30-40 \mathrm{~cm})$, with slopes greater than $-0.02-0.025$. Carrying out watering on the furrows is difficult, because of the complex terrain. Therefore, it was planned to sprinkle with small norms, using micro-razors of various modifications.

Water supply for irrigation in these areas (with a total area of more than 8 hectares) was carried out from hydrants installed through 85, 120, $200 \mathrm{~m}$ on the corresponding transport pipelines, into open sprinklers (at a rate of $60,80,100120 \mathrm{I} / \mathrm{sec}$ ), cut Perpendicular to it. It was found that at irrigation rates of 300-420 m3 / ha the soil is soaked to insignificant depth (20-30, sometimes up to $40 \mathrm{~cm})$. The low absorption rate of the upper soil layer and large slopes provided a significant surface discharge (30\%), increasing from irrigation to irrigation. The addition of moisture in the soil was only 100-300 m3 / ha. Small irrigation rates require private watering (after 5-6 days). The supply of large irrigation norms (600-700 $\mathrm{m3} /$ ha and more) is difficult due to a mismatch in the intensity of the rain $(2-3 \mathrm{~mm} / \mathrm{min})$ and the rate of water absorption into the soil. Large drops of rain 
destroy the structure of the soil, and the upper 2-3 cm are swollen; The absorption rate decreases, resulting in a surface discharge. Then, an experimental site for micro-irrigation for watering vineyards, soybeans, sugar beet, corn for silage, fruit trees was organized, in the territory of Ganja RACC of the village. B / Bagmanli with an area of 4.1 hectares and AIA of the Agricultural Research Institute of the Terter region with an area of 1.5 hectares.

The soils of the site (with a total area of more than 30 hectares) are average loans, gradients of 0.005 (Fig.). And so in 2007-2009 irrigation norm was performed with irrigation norm of $3700-4200 \mathrm{~m} 3$ / ha (irrigation norms from 350 to $550 \mathrm{m3}$ / ha). Moisture in the $60 \mathrm{~cm}$ layer did not drop below $60 \%$ of the PPV, and after irrigation, it was $80-90 \%$ of the PPV. Soaking of the soil was no more than $30-50 \mathrm{~cm}$ (most of the water in the $20 \mathrm{~cm}$ layer).

The yield for soybean production was $14-17$ c / ha. In 2010, late-spring water recharge was performed on the upper part of the site (with an area of 0.6 hectares) (the groundwater level here was deep, and the rest of the site varied from 2 to $5.5 \mathrm{~m}$ ).

Reserves of moisture in the soil were insufficient to produce shoots, so in mid-May, the reseeding was carried out after the presowing irrigation with the norm of 250-300 m3 / ha.

Where, irrigation was conducted in this period with an irrigation rate of 3800-4200 m3 / ha. Further all this work was expanded in the Samukhian area of corn on the trees and mulberry trees, in the Shamakhi district in vineyards, in the Guba district of fruit gardens, Khachmas district of vegetable crops (cabbage, eggplant).Studies on sprinkling in this facility have shown that the rainfall in the IDAUD $(3 \mathrm{~mm} / \mathrm{min})$ is greater than the rate of water absorption into the soil of the research object. Therefore, when feeding $500 \mathrm{~m}^{3} /$ ha, puddles and surface discharges were formed at the site.

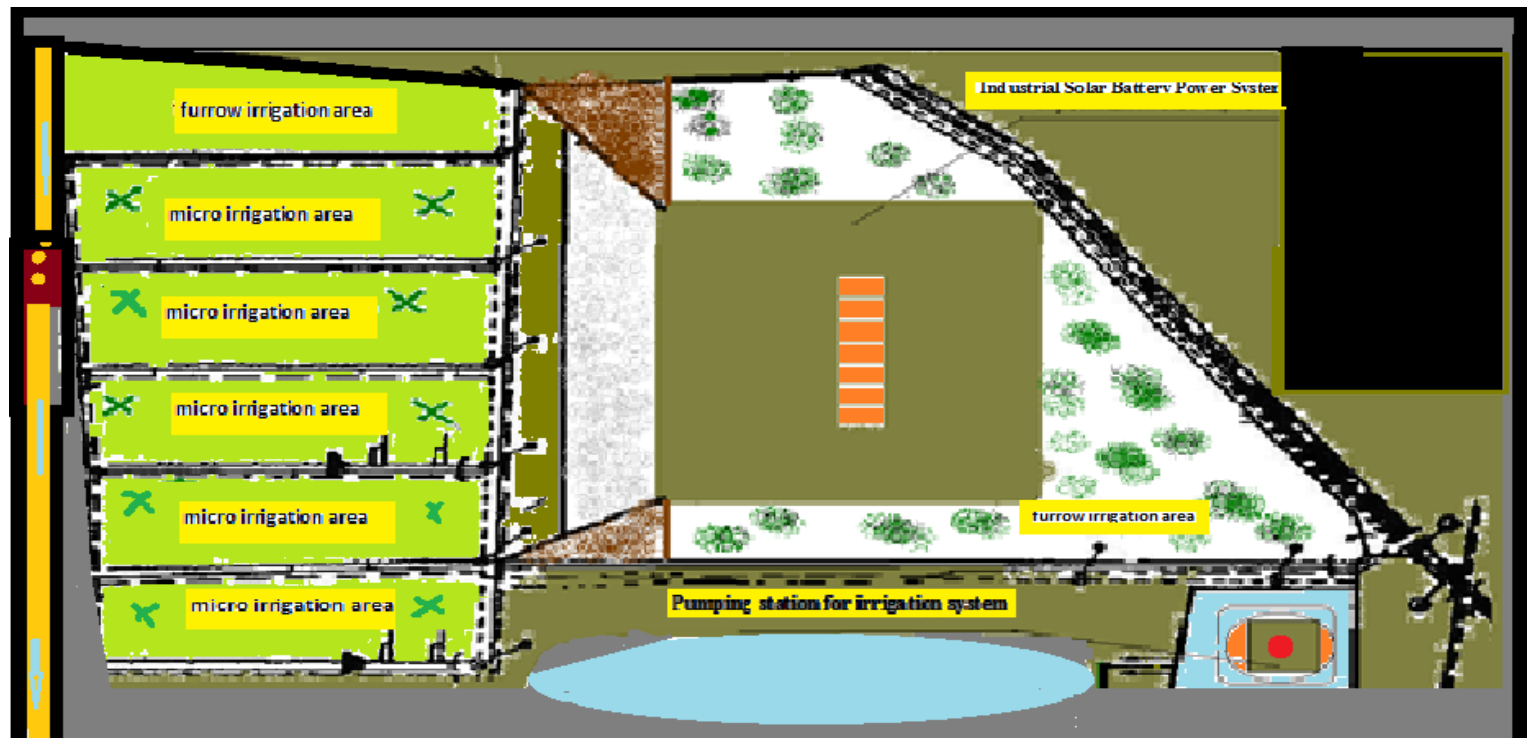

Fig.2. Scheme of the irrigation sprinkling station on the experimental part of the Terter RACS in the Garabagh land in the period 2006-2010 with the use of the Idad and MDR sprinklers: 


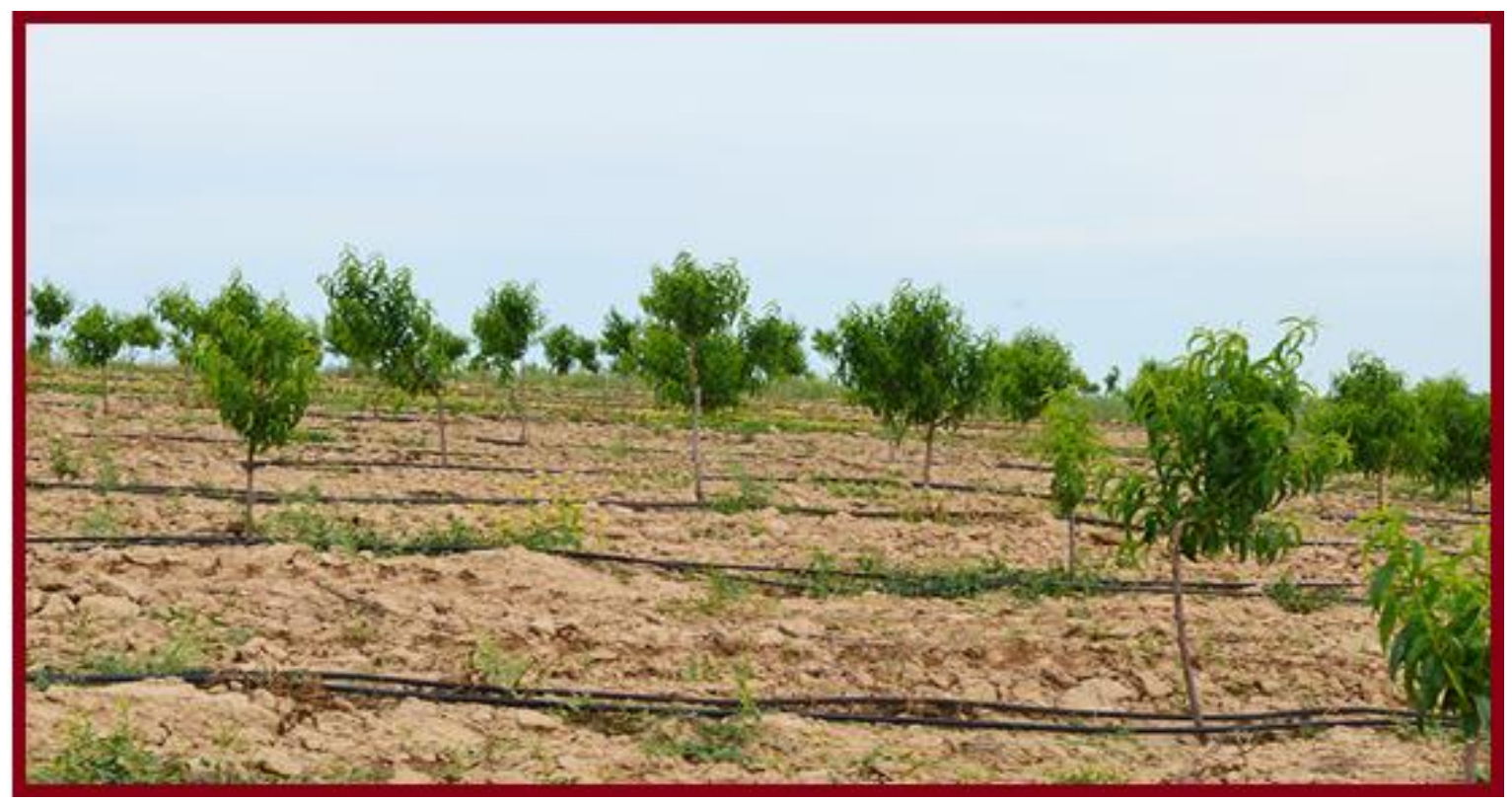

Fig.3. Demonstration of the micro-irrigation regime using drip irrigation of fruit trees in the conditions of the EIA of the Research Institute of Erosion and Irrigation in the Shamakhi district in the village of Malkham.

The discharge was $20-30 \%$, which led to uneven moistening. At the beginning of vegetation due to timely treatments, the surface discharge decreased (up to $8-10 \%$ ). When the treatment of crops ceased, the discharge again reached $16-17 \%$.

Soaking of the soil during watering did not exceed $30-60 \mathrm{~cm}$. Greater wetting and better uniform moisture distribution under these conditions is achieved with irrigation rates of more than $300-400 \mathrm{~m} 3 /$ ha. At such rates about $60-70 \%$ of water remains in the upper $(20 \mathrm{~cm})$ layer, and the plants are not completely supplied with moisture. A big drawback with the irrigation of the Idad apparatus in the presence of an irrigation network, impassable for machining mechanisms. It was found out that sprinklers and roads along them occupy $6-8 \%$ of the area; For example, in this case, water losses in irrigation systems built in the Guba RRCN were 30-35\% per 1 $\mathrm{km}$, and in Terter AOS 20-25\% 
Table 2. Conditions for microregulation of vehicles of irrigation systems in the territory objects study

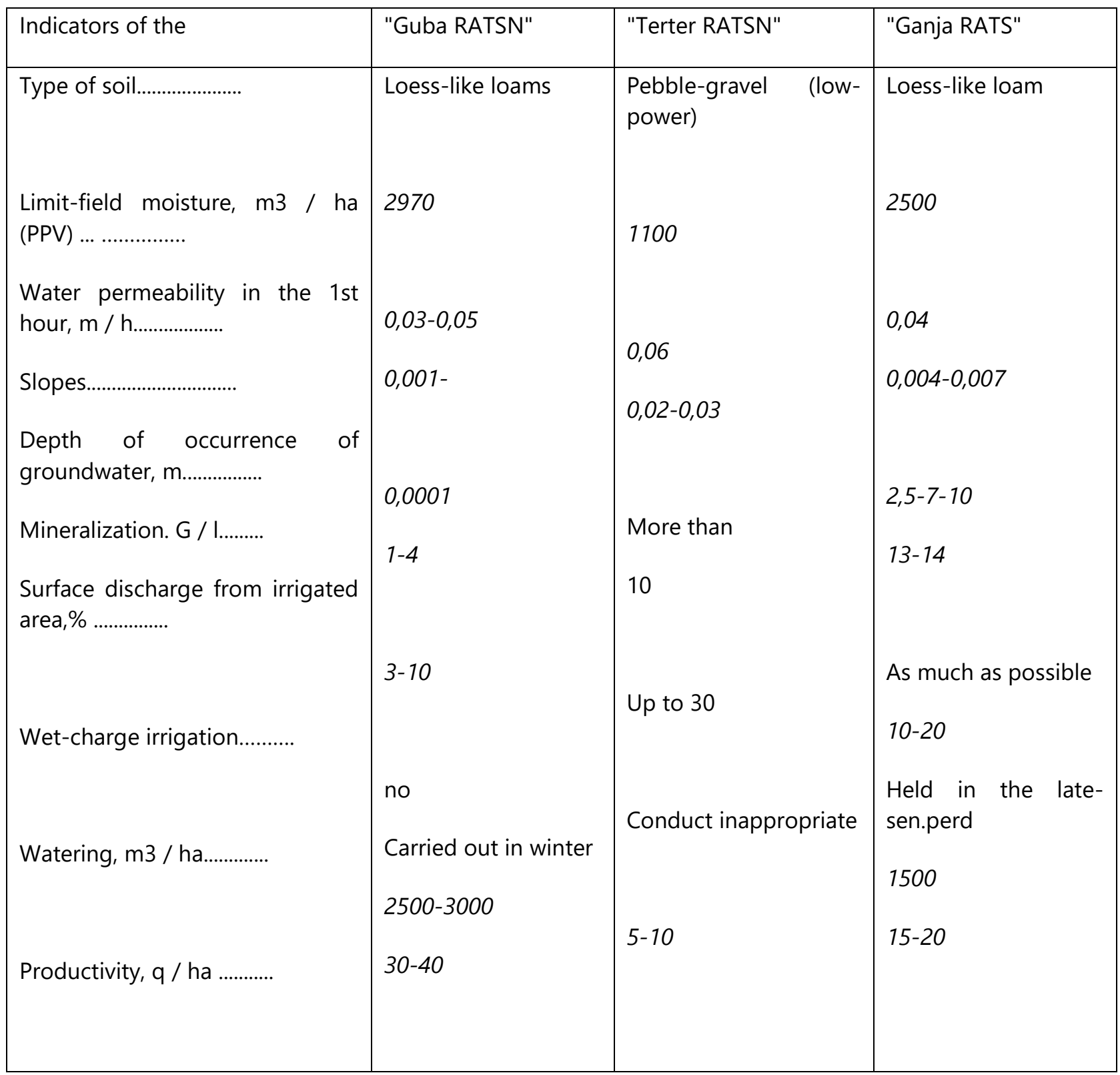

The distribution of water in micro-irrigation according to calculations (according to B.H.Aliyev's method) was as follows (Table 3).

At the same time, the greatest losses occurred in the discharge and evaporation. 
Table 3.

Water balance during sprinkling in the experimental areas of Terter, Shamakhi and Ganja RACS

\begin{tabular}{|c|c|c|c|c|c|c|}
\hline \multirow[t]{2}{*}{ Balance sheet items } & \multicolumn{2}{|c|}{ Ganja RATSN } & \multicolumn{2}{|c|}{ Terter RATSN } & \multicolumn{2}{|c|}{ Shamakhi RATSN } \\
\hline & $\mathrm{M}^{3} / \mathrm{ha}$ & $\%$ & $\mathrm{~m}^{3} / \mathrm{ha}$ & $\%$ & $\mathrm{M}^{3} / \mathrm{ha}$ & $\%$ \\
\hline $\begin{array}{l}\text { Coming................... } \\
\text { Total:....................... } \\
\text { Including } \\
\text { - filtration into the soil } \\
\text { - exact volume ....... } \\
\text { Evaporation when rain } \\
\text { drops fall to the ground... } \\
\text { "Reset from the field....... } \\
\text { Left on the field............ }\end{array}$ & $\begin{array}{l}644 \\
644 \\
16,2 \\
7,1\end{array}$ & $\begin{array}{l}12,6 \\
13,4 \\
70,30\end{array}$ & $\begin{array}{l}693,7 \\
693,7 \\
55,7 \\
10,0\end{array}$ & $\begin{array}{l}12,7 \\
23,4 \\
54,5\end{array}$ & $\begin{array}{l}86,3 \\
183,4 \\
484,8\end{array}$ & $\begin{array}{l}14,1 \\
197 \\
42,07\end{array}$ \\
\hline
\end{tabular}

Irrigated standards for various soils and slopes, under which the runoff of water begins, where the results of the study are shown in Table. 4.

Table 4.

Irrigated norms ( $\mathrm{m}^{3} / \mathrm{ha}$ ) before the appearance of runoff based on the results of the conducted study in the regions of Guba-Khachmaz and Ganja-Gazakh zone

\begin{tabular}{|l|l|l|l|l|}
\hline \multirow{2}{*}{ Soil } & \multicolumn{2}{l|}{ Slopes } & \multicolumn{2}{l|}{$\mathbf{0 , 0 0 2 - 0 , 0 0 7}$} \\
\cline { 2 - 5 } & \multicolumn{2}{|l|}{$\mathbf{0 , 0 0 0 2 - 0 , 0 0 0 5}$} & First watering & $\begin{array}{l}\text { Last } \\
\text { watering }\end{array}$ \\
\cline { 2 - 5 } & First watering & $\begin{array}{l}\text { Last } \\
\text { watering }\end{array}$ & & 170 \\
\hline Sandy loam ........... & 450 & 230 & 400 & 100 \\
Light loam .............. & 340 & 150 & 290 & 80 \\
\hline
\end{tabular}


According to prof.B.H. Aliyev, the surface discharge in the Guba RNCN zone during watering of apple gardens on the territory of the experimental plot is $7-8 \%$ until August, and in August $-20 \%$, which testifies to the results of the research in the period 2006-2011.

It should be noted that even according to the results of the studies carried out in the Terter region on small slopes and fertile soils, where fields are leveled annually, even after feeding 350-400 m3 / ha, puddles appear on the surface of the field. When testing the IDAA with deflector nozzles both in the Guba-Khachmaz RADSN and in the Terter AOS (rain intensity $0.7-1.2 \mathrm{~mm} / \mathrm{min}$ ), positionally, the formation of puddles and runoff on medium and heavy soils at irrigational norms of $250-300 \mathrm{~m}^{3} /$ ha.

Small irrigation rates (before the formation of runoff) require a large number of irrigation.

Thus, in the Shemakha region, in the experiments carried out by the Shamakhi ElA of the Institute of Erosion and Irrigation of ANAS (4.8 ha) on heavy soils with a deep bedding of groundwater at the same irrigation rate (7000-7500 m3 / ha), the number of irrigations with micro-irrigation (42-53) Was significantly larger than in the case of furrows along furrows (6-8). To combat cortex and compaction, it was necessary to sharply increase the number of interrow treatments (up to 10), which did not completely destroy the crust near the stem. Shallow and uneven soaking of the soil and untimely processing of crops led to a marked reduction in yield during sprinkling.

Production experiments on micro-irrigation were carried out in the Zakatala district. The tests of sprinkler technology such as IDAD, MDP, MDR and developed by us have established that with a deep level of groundwater and a complex relief, the use of IDA, on watering tobacco and corn, apple, etc. is more promising than other dominant traditional (surface) methods of irrigation.

The results of the test revealed that to reduce the intensity of rain on the sprinkling heads of the apparatus, special nozzles-vichrators were mounted for sprinkling up to $40 \mathrm{~m}$ in radius and more than the action and added additional devices for regulating the rain layer, which helped to suppress pressure in the pump discharge port

All this allowed to reduce the intensity of rain and give irrigation rates of 600-700 m3 / ha (with a daily mode of operation) without significant surface discharge and soil erosion. Such measures can reduce run-off, but this reduces labor productivity in watering. However, it is also difficult to equip sprinklers with a higher water delivery rate in the range of $800-1000 \mathrm{~m} 3 /$ ha, where significant planning work is required.

The proposed nozzles installed on the ISAD sprinkler have a relatively low rain intensity, which is explained by the desire to create a microclimate over plants with low water consumption, with limited geometry of the irrigated area.

Experience proves that with increasing capture width, it would be possible to reduce the intensity of rain while retaining labor productivity.

The experimental work carried out by us at the above-mentioned research facilities in Terter, Zagatala and Ganja on irrigating soybeans, sugar beet, maize and tobacco makes it possible to give an approximate average rain intensity ( $\mathrm{mm} / \mathrm{min}$ ) at irrigation rates of 300-500 m3 / ha, depending on the soils: Sandy -0,3 0,4, light loamy $0,20,3$, medium and heavy loam -0,1 0,2.Apparently, a wide production check of this irrigation technology, taking into account the recommended rain intensity, will allow us to clarify the technical and economic indicators and the conditions for the application of micro-irrigation. 


\section{Conclusions:}

The analysis has shown that irrigation with micro-irrigation can also find its spread in conditions of close lying of non-saline groundwater.

At a high level of groundwater, high yields of agricultural crops can be achieved, however, technical and economic indicators at the given level of development of sprinkling equipment in the presence of socioeconomic conditions of life of farming and other farms of the republic are less favorable than surface furrow irrigation.

Further improvement of sprinkler systems with higher technical and economic indicators, possibly, will allow to expand irrigation area of micro-irrigation in conditions of mountain-irrigated agriculture in Azerbaijan. For this purpose, in the future, micro irrigation systems of the type IDAD and others proposed for serial production were not tested in the republic for any more (except for research objects) for sprinkling.

\section{LITERARY SOURCES}

1. Aliyev Z. H., Aliyev B.H. "Impulslo Su Burakhyo." Patent No. P 20020196, Baky 2002,III.

2. Aliyev Z. H., Aliyev B. H., NurievCh.Sh. / "Asta yağışyağdıran qurğular systems" Patent No. R.990100 Baka 1999-s il.

3. Aliyev Z.H. "Suvarma sistemlərinin optimallaşdırilması" / Patent No. I. 99001624.

4. $\quad$ Aliyev Z.H., Aliyev B.H. "Impulslu suburaxıcı" / Patent No. I. 20000152.

5. Aliev ZH. Development and implementation of a pulse-sprinkling device for auto oscillatory action in the mountainous and foothill region of Azerbaijan: Abstract of the dissertation. Candidate of Agricultural Sciences.Baku, 2003.

6. Aliev B.H. Aliev ZH, "Irrigation techniques for farmers and peasant farms in Azerbaijan" / Monograph, "Azerneshr" Publishing House Baku, 1998.113

7. Aliev B.H. Aliyev ZH, Zoning of the territory of the Republic of Azerbaijan for the selection of progressive irrigation technology. / Monograph, Ziyaya Publishing House. Baku, 2001. 297

8. Aliev B.H. Aliyev ZH, Irrigated agriculture in the mountain and foothill regions of Azerbaijan. / Monograph Publishing house "Ziya-Nurlan EPP LLC", Baku, 2003. 330 p.

9. Aliyev Z.H.- A research report on the model-experimental study of runoff and runoff from rainwater using various soil protection techniques on winter pastures with dissected relief of the southeastern part of the Greater Caucasus, manuscript of the Research Institute of Erosion and Irrigation, Baku-2004, p. 76. 